\title{
An Exploratory Investigation Of College Students' Attitudes Toward California's New Menu-Labeling Law
}

Pinar Avcibasioglu, California State University at Northridge, USA Jessica Cardinale, California State University at Northridge, USA Curt J. Dommeyer, California State University at Northridge, USA Violetta Lebioda-Skoczen, California State University at Northridge, USA Julie Liu Schettig, California State University at Northridge, USA

\begin{abstract}
In March of 2009, business students at a large public university in the Los Angeles area were polled about their attitudes towards a new menu-labeling law that was about to be implemented in California. It was hypothesized that the students would be in favor of the law and that those in favor of it would be inclined to select healthier items on the menu. Moreover, it was hypothesized that the law would be favored more by females than males, and more by persons who perceive themselves as overweight than those who perceive themselves as average weight. Support was found for all of the hypotheses except for the one concerning a person's perceived weight status. A student's perceived weight status appears to have no effect on his or her reaction to the new menu-labeling law. The survey results indicate that menu-labeling will be effective in promoting better eating habits among college students who dine out.
\end{abstract}

Keywords: Menu-Labeling; Nutrition Labeling; Adolescent Obesity

\section{INTRODUCTION}

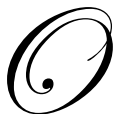

ver consumption of food is a problem that plagues many Americans. Recent research reveals that at least one-third of all Americans aged 20 and over are overweight or obese (Ogden, Carroll, and Flegal, 2008; Ogden, Carroll, McDowell, and Flegal, 2007). Numerous medical conditions are associated with over eating, namely type 2 diabetes, heart disease, hypertension, stroke, arthritis, fatty liver disease, gallbladder disease, sleep apnea and certain cancers. Health problems associated with overweight individuals were estimated to account for approximately 9.1 percent of all U.S. medical expenditures in 1998, an amount that may have reached as high as $\$ 78.5$ billion in 1998 dollars (Finkelstein, Fiebelkorn, and Wang, 2003). Kozup, Creyer and Burton (2003) estimated that at least 300,000 people die annually in the United States due to health conditions caused by individuals being overweight or obese.

The Nutritional Labeling and Education Act of 1990 (NLEA) resulted in the Nutrition Facts Panel being placed on most food packages. Consequently, consumers who purchase packaged food items usually have the ability to learn the nutritional content of the food they buy. People, however, do not purchase all of their food in labeled packages from supermarkets. It is estimated that almost one-third of consumers' meals are eaten at restaurants (Shapiro, 1995). Moreover, approximately 74\% of all restaurant meals are eaten at fast food restaurants, and these restaurants typically sell meals that have a high calorie content (Bassett et al., 2008). Restaurants, unfortunately, are exempt from the NLEA requirements unless they make a specific nutritional claim, e.g., "this food his heart healthy." Therefore, in most cases, restaurant consumers have a limited understanding of the nutritional content of the restaurant food they are consuming. In a study conducted by Burton, Creyer, Kees, and Huggins (2006), consumers were polled about the calorie content of several restaurant items. On average, they underestimated the calorie content of the "less healthful items" by 642 calories. For example, one item containing 3010 calories (cheese fries with ranch dressing) was typically estimated to have a little over a 1,000 calories. Even 
trained dietitians underestimate the calorie content of restaurant items by 220 to 680 calories (Backstrand, Wootan, Young and Hurley, 1997). Because of the lack of nutritional information available to restaurant patrons, most consumers probably do not realize that a single restaurant meal can contain more than a full day's supply of calories and saturated fat (Anonymous, 2004; Hurley and Schmidt, 1966).

College students, in particular, are in an environment that is conducive to being overweight. College students are the target of many food manufacturers that offer inexpensive foods that are loaded with calories, sugar, and fat. Moreover, many college students tend to be physically inactive, have little time and ability to cook nutritious meals at home, and are exposed to large portion sizes at a variety of eating facilities (Brownell, Schwartz, Puhl, Henderson, and Harris, 2009). Strategies that educate students about the merits and demerits of the restaurant food they are exposed to may reduce college student obesity and prevent their becoming obese in later life.

One way to educate consumers about the nutritional content of the restaurant food they eat is to require restaurants to use menus that disclose the nutritional content of the meals offered. Menu labeling laws have already been in effect for over a year in three locations: Washington State's King County, New York City, and Westchester County (a suburb of New York). In July of 2009, the State of California implemented a law that requires chain restaurants with 20 or more branches to provide nutritional information on their menus. For each meal offered, the menu must disclose the following information: total number of calories, grams of saturated fat, grams of trans fat, and milligrams of sodium.

Menu-labeling appears to promote healthier eating. New York City residents were surveyed to determine how menu labeling has affected their menu choices. Most of the respondents indicated that they now seek out lower calorie options on the menu (Gregory, 2009). In another study, a survey of Subway customers showed that customers who saw the calorie content of the menu items were more likely than those who did not see the calorie information to order meals with fewer calories (Bassett et al., 2008). Another study was conducted among cafeteria patrons at Kaiser Permanente Hospitals. This study found that cafeteria patrons were more likely to select healthy eating options when calorie information was placed on menus (Anonymous, 2009a).

As already mentioned, college students are particularly vulnerable to poor eating habits. The purpose of the present study is to determine business students' attitudes toward the new California law that requires some chain restaurants to disclose the nutritional content of their meals.

Four research hypotheses are proposed. First, it is hypothesized that California business students will be in favor of the new menu-labeling law since it should lead to more informed and healthier decisions when selecting restaurant meals. Moreover, previous research has shown that the vast majority of Americans favor having nutritional information on menus (Anonymous, 2009b; Anonymous, 2009c; Wootan and Osborn, 2006). Second, it is predicted that the new menu-labeling law will motivate students to select menu items that are lower in calories on the menu. Previous research has shown that consumers not only underestimate the number of calories for items on the menu, but they also tend to choose lower calorie items from the menu once they are educated about the caloric content of the items that are offered (Bassett et al., 2008, Burton et al., 2006; Gregory, 2009). Third, it is hypothesized that females will be more likely than males to favor California's new menu-labeling law. This hypothesis is based on the fact that women appear more likely than men to use food labels. Smith, Taylor and Stephen (2000) found that women students were four times more likely than males to pay attention to food labels. Similarly, Byrd-Bredbenneer (2000) and Huang et al. (2004) found that young females were more likely than their male counterparts to read food labels. Fourth, it is predicted that students who perceive themselves as overweight will be more in favor of the new menu-labeling law than students who perceive themselves as average weight. This hypothesis is predicated on the assumption that overweight students will be motivated to lose weight and therefore should appreciate knowing the calorie content of the food they may order in a restaurant.

\section{METHODOLOGY}

The new menu-labeling law in California was implemented on July 1, 2009. Prior to the implementation of the new law - in late March of 2009 - students walking into the business building at a large public university in the Los Angeles area were asked to participate in a survey about the new menu-labeling law. Students who consented 
to the survey were handed a self-administered questionnaire along with a pre-addressed, stamped envelope. They were told that they could complete the survey at their convenience and return it by mail. A total of 304 surveys attempts were made from March $20^{\text {th }}$ until March $24^{\text {th }}$ of 2009.

Respondents were first queried about the factors that affect their decision when ordering a restaurant meal. It was hoped that this question would reveal the extent to which calorie information is important to students when selecting a meal.

Later in the survey, respondents were asked of their awareness of the new menu-labeling law. Once the new labeling law was described to them, they were asked how they felt about the new law, i.e., whether they were or were not in favor of the law. Subjects were then asked to indicate their degree of agreement or disagreement with a set of belief statements that inquired about their motivation for either favoring or not favoring the new law. To determine how students might react to the new law once it was enacted, they were placed in a hypothetical situation where they were to learn their typical restaurant meal contained calorie values that were much higher than they expected. They were then asked to indicate if this calorie information would affect their meal decision and, if so, to elaborate on how it might affect their decision. Finally, subjects were asked to provide some demographic and lifestyle information.

\section{RESULTS}

\section{The Respondents}

The survey response rate was $23 \%$, as 69 students provided a usable response to the survey. It is presumed that most of the respondents are business students since the data was collected in a building that caters only to business students.

Fifty-five percent of the respondents are female, $67 \%$ are in the 20 to 29 age bracket, and $71 \%$ reported an annual income of $\$ 80,000$ or less. They represent a variety of races: $38 \%$ are Caucasian, $22 \%$ are Asian, $20 \%$ are Hispanic, 6\% are African-American, and the balance indicated the "other" category. Most of the respondents appear to be good students, as $65 \%$ reported a university grade point average of 3.01 or above.

As for lifestyle characteristics, $26 \%$ reported they were either an occasional or regular smoker, $60 \%$ indicated they were infrequent exercisers, and $77 \%$ indicated they ate out at restaurants at least two to three times a week. When asked how they viewed their weight, $25 \%$ felt they were overweight, $66 \%$ felt they were average weight, and $9 \%$ felt they were underweight.

\section{Survey Results}

The respondents were presented with five meal factors - price, portion size, ingredients, calorie amount, and "other" - and asked to indicate which factor or factors they considered when selecting a meal. The most popular factor was price, as it was selected by $78 \%$ of the respondents. This factor was followed in popularity by ingredients $(68 \%)$, portion size $(45 \%)$, calorie amount $(30 \%)$, and "other" (14\%). These results suggest that calorie information may be a relevant meal factor to no more than a third of the students.

After the new Menu-Labeling Act was described on the survey, each respondent was asked if he or she had heard of the law. Only $36 \%$ of the respondents reported hearing of the law, and only $17 \%$ indicated that they knew that the first provisions of the law would be implemented in early July of 2009. Although students' knowledge of the upcoming law was lacking, their interest in the new law appears to be strong. Seventy-five percent of the respondents indicated that calorie information should be required on restaurant menus. Moreover, $67 \%$ of the respondents indicated they would vote for a new law that required menus to be labeled with nutritional information. These latter results support the first hypothesis.

To determine students' reaction to the new menu-labeling law, respondents were asked to use a five-point Likert scale to indicate their degree of agreement or disagreement with several statements reflecting beliefs about 
the new law. For each statement, a score below three represents "disagreement" while a score above three indicates "agreement." The results from the belief statements indicate that those students who favored the new law $(\mathrm{n}=52)$ felt that it would make them more informed decision makers (mean $=4.51$ ), felt the new information on the menus would not hurt anything (mean $=4.46$ ), felt that restaurants might not disclose the calorie information unless required to $($ mean $=3.79)$, and felt that new law might help improve people's health $($ mean $=3.49)$. Those who were against the new law $(n=17)$ felt that they did not need any help in making their meal decisions $($ mean $=4.20)$, thought the nutritional information on the menu would hinder the menu's appearance (mean $=3.90$ ), were against government regulation (mean $=3.86$ ), and indicated a desire to avoid calorie information when eating out $($ mean $=$ $3.70)$.

To determine how students might react to the new menu-labeling law after it is implemented, they were asked the following hypothetical question: "If the calorie information was provided on menus and you learned that your typical meal had calorie values much higher than you expected, would this information impact your meal purchasing decisions?" Of those responding to this question ( $\mathrm{n}=69), 62 \%$ indicated "yes," $24 \%$ indicated "no," and $13 \%$ were "undecided." Those responding affirmatively to this question were then asked to use a five-point Likert scale (where " $1 "$ = strongly disagree and " 5 " = strongly agree) to elaborate on their previous answer by responding to a set of belief statements that focused on their reaction to the hypothetical situation. Those who indicated the calorie information would affect their meal decision $(\mathrm{n}=43)$ tended to agree with the following statements: "I would seek out and order lower calorie alternatives" $($ mean $=4.13)$ and "I would no longer order certain items" (mean = 3.86). These results support the second hypothesis.

\section{The Effect of Student's Gender}

To determine whether a student's gender affects his or her reaction to the new menu-labeling law, several one-sided Fisher's Exact Tests were run at the .10 significance level. With each test, the 38 males and 31 females were compared on their answers to each of the following questions:

1. Have you heard about "The Menu Labeling Act (SB 1420)" which requires restaurants to post calorie information on their menus and indoor menu boards? (Yes vs. No)

2. Do you believe that calorie information should be required on restaurant menus? (Yes vs. No)

3. Would you vote for a law requiring restaurants to provide calorie information on their menus? (Yes vs. No)

4. If the calorie information was provided on menus and you learned that your typical meal had calorie values much higher than you expected, would this information impact your meal purchasing decision? (Yes vs. No)

There was no significant difference between males' and females' tendency to be aware of the new menulabeling law (question 1). Females, however, appeared more interested in the law than males as they were more likely to believe that calorie information should be required on menus $(84 \%$ vs. $65 \%, \mathrm{p}<.06)$, more likely to vote for a menu-labeling law $(79 \%$ vs. $52 \%, \mathrm{p}<.02)$, and more likely to indicate that having calorie information on the menu would affect their meal decision $(83 \%$ vs. $56 \%, \mathrm{p}<.03)$. These results support the third hypothesis.

\section{The Effect of Student's Perceived Weight Status}

When students were asked to indicate their weight status, 17 classified themselves as "overweight" while 45 classified themselves as "average weight." To determine whether a student's perceived weight status affected his or her reaction to the menu-labeling law, the two weight groups were compared on their answers to the four questions analyzed in the previous gender analysis. Similar to the gender analysis, one-sided Fisher's Exact Tests run at the .10 significance level were used to compare the two groups

There were no significant differences between the two weight groups on the four questions that were analyzed. Therefore, the fourth hypothesis is not supported 


\section{DISCUSSION AND CONCLUSIONS}

Three of the four hypotheses were supported by the data. It was found not only that the majority of students are in favor of the new menu-labeling law, but also that those students favoring the law would be inclined to select lower calorie items and to avoid items that are presumably unhealthy. Moreover, it was found that females are more likely than males to be in favor of menu-labeling and that females are more likely to select their meal based on the meal's content. The results suggest that California's menu-labeling law should result in healthier restaurant meal selections from college students, especially females.

No support was found for the fourth hypothesis which predicted that students who perceive themselves as overweight will be more in favor of the new menu-labeling law than students who perceive themselves as average weight. Of these two groups, it was assumed that the overweight group would be more concerned about the content of the food they were ingesting. The assumption that was made about which group is more motivated to watch the food they eat may be wrong. It could be that overweight people are overweight precisely because they are not careful about the food they ingest. The overweight students may be no more concerned about the content of the food they consume than the average weight people. Rather than asking people about their perceived weight status, it might be more meaningful to ask people if they have a motivation to gain or lose weight. Those who are motivated to change their weight will most likely be the ones who favor menu-labeling.

The present study is limited to business students and to a small convenience sample. Moreover, the survey relied primarily on structured questions, and it is possible that more depth and variety of response could have been achieved by using unstructured questions. In addition, since all of the belief statements used in this study were positively worded, the responses to those statements could have been subject to an acquiescence response bias. Perhaps more accurate results could have been obtained if a mixture of positively and negatively worded belief statements had been used (Schriesheim and Hill, 1981).

As of this writing, California's new menu-labeling law has been implemented, and many questions remain to be answered about the effects of the law. For example, to what extent are the restaurants following the provisions of the law? Are restaurants changing the ingredients of their current offerings so that they will appear to have a healthy content? Are restaurants adding new items to the menu that cater to the health-oriented consumer? Are consumers noticing the menu-labeling? Is the menu-labeling affecting which restaurant a consumer selects or the meal that is ordered? Is the menu-labeling affecting the amount of business a restaurant gets? Does menu-labeling detract from the menu or diminish the experience of dining out? Hopefully, future researchers can provide answers to these questions.

\section{AUTHOR INFORMATION}

Pinar R. Avcibasioglu earned her MBA from California State University, Northridge and her undergraduate degree in Business Administration from the University of Istanbul. She has six years of professional work experience in marketing, customer business development and brand management, mostly in the cosmetics and pharmaceutical industries. She is interested in business to business marketing, marketing research, competitor evaluation and strategy implementation.

Jessica Cardinale earned her MBA from California State University, Northridge and her BS in Business Administration from California Polytechnic State University, San Luis Obispo. She currently works for Hamagami Carroll Inc. in Los Angeles, California as a senior project manager overseeing online and offline branding and marketing campaigns for various corporate and home entertainment clients. She is interested in brand management and consumer buyer behavior market research.

Curt J. Dommeyer earned his Ph.D. in Business Administration from the University of Cincinnati and his MBA from Santa Clara University. For the past 33 years, he has taught marketing at California State University, Northridge. During four of those years, he served as Chair of the Department of Marketing. He has over 40 publications in refereed journals and conference proceedings. His current research interests include business etiquette, pedagogy, identity theft, and survey methodology. 
Violetta Lebioda-Skoczen earned her MBA with a concentration in Marketing from California State University, Northridge and her Masters in Economics from Opole University in Poland. For the past ten years, she has worked in the Finance Department at Oldcastle Glass, a supplier of building envelope products. She is interested in pursuing a career that involves marketing research and consumer behavior.

Julie Liu Schettig earned her MBA from California State University, Northridge and her BA in Film and Digital Media from the University of California, Santa Cruz. She currently works for Warner Brothers in Burbank, California as a media analyst focusing on offline advertising for various home video and video game releases. She is interested in entertainment marketing and traditional and non-traditional advertising research.

\section{REFERENCES}

1. Anonymous, Eating at Fast-food Restaurants More than Twice per Week Is Associated with More Weight Gain and Insulin Resistance in Otherwise Healthy Young Adults, National Institutes of Health News, news release, December 30. Retrieved September 22, 2009 from http://www.nhlbi.nih.gov/new/press/04-1230.htm, 2004.

2. Anonymous, Kaiser Permanente to Provide Calorie, Nutrition Information on Cafeteria Menus; UC Berkeley Study Shows That Menu Labeling Increases Patrons Choice of Healthy Menu Options, PR Newswire, July $27^{\text {th }}$, 2009a.

3. Anonymous, Diet Now. Health, Vol. 23, No. 2, March, p. 20, 2009 b.

4. Anonymous, Restaurants: Congress Should Pass Menu Labeling Provision, but Make it Broader, Business Wire (New York), July $21^{\text {st }}, 2009 \mathrm{c}$.

5. Backstrand J., M.G. Wootan, L. R. Young, and J. Hurley, Fat Chance. Washington, DC: Center for Science in the Public Interest, 1997.

6. Bassett, M. T., T. Dumanovsky, C. Huang, L.D. Silver, C. Young, C. Nonas, T. D. Matte, S. Chideya, and T. R. Frieden, Purchasing Behavior and Calorie Information at Fast-food Chains in New York City, 2007, American Journal of Public Health, Vol. 98, No. 8, pp. 1457-1459, 2008.

7. Brownell, K. D., M. B. Schwartz, R. M. Puhl, K. E. Henderson, and J. L. Harris, The Need for Bold Action to Prevent Adolescent Obesity, Journal of Adolescent Health, Vol. 45, No. 3, pp. S8-S17, 2009.

8. Burton, S., E. H. Creyer, J. Kees, and K. Huggins, Attacking the Obesity Epidemic: the Potential Health Benefits of Providing Nutrition Information in Restaurants, American Journal of Public Health, Vol. 96, No. 9, pp. 1669-1675, 2006.

9. Byrd-Bredbenner, C., The Ability of College Women Aged 17-25 to Perform Tasks Using Nutrition Facts Labels, International Electronic Journal of Health Education, Vol. 3, pp. 97-106, 2000.

10. Finkelstein, E. A., I.C. Fiebelkorn, and G. Wang, National Medical Spending Attributable to Overweight and Obesity: How Much, and Who's Paying? Health Affairs, Vol. W3, pp. 219-226, 2003.

11. Gregory, S., Calorie-Conscious Menus, Time, Vol. 173, No. 25, June 29 $9^{\text {th }}$, pp. 45-46, 2009.

12. Huang, T. T., H. Kaur, K. S. McCarter, N. Nazir, W. S. Choi, and J. S. Ahluwalia, Reading Nutrition Labels and Fat Consumption in Adolescents, Journal of Adolescent Health, Vol. 35, pp. 399-401, 2004.

13. Hurley, J. and S. Schmidt, Hard Artery Café? Nutrition Action Health Letter, October, pp. 1-7, 1996.

14. Kozup, J. C., E. H. Creyer, and S. Burton, Making Healthful Food Choices: The Influence of Health Claims and Nutrition Information on Consumers' Evaluations of Packaged Food Products and Restaurant Menu Items, Journal of Marketing, Vol. 67, April, pp.19-34, 2003.

15. Ogden, C. L., M. D. Carroll, and K. M. Flegal, High Body Mass Index for Age among Us Children and Adolescents, 2003-2006, The Journal of the American Medical Association, Vol. 299, No. 20, pp. 24012405, 2008.

16. Ogden, C. L., M. D. Carroll, M. A. McDowell, and K. M. Flegal, Obesity among Adults in the United States - No Statistical Change since 2003 -2004. Retrieved September 10, 2009 from http://www.ncbi.nlm.nih.gov/pubmed/19389313, 2007.

17. Schriesheim, C. A. and K. D. Hill, Controlling Acquiescence Response Bias by Item Reversals: the Effect on Questionnaire Validity, Educational and Psychological Measurement, Vol. 41 No. 4, pp. 1101-1114, 1981.

18. Shapiro, R., Review of the Nutrition Labeling and Education Act Regulations, in Nutrition Labeling Handbook, Ralph Shapiro, ed., New York: Marcel Dekker, pp.125-226, 1995. 
19. Smith, S. C., J. G. Taylor, and A. M. Stephen, Use of Food Labels and Beliefs about Diet-disease

Relationships among University Students, Public Health Nutrition, Vol. 3, pp. 175 - 182, 2000.

20. Wootan, M. G., and M. Osborn, Availability of Nutrition Information from Chain Restaurants in the United States, American Journal of Preventive Medicine, Vol. 30, No. 3, pp. 266-268, 2006. 
NOTES 